\title{
SYSTEM DYNAMICS MODELING FOR CONSTRUCTION MANAGEMENT RESEARCH: CRITICAL REVIEW AND FUTURE TRENDS
}

\author{
Mingqiang LIU ${ }^{1,2}$, Yun LE ${ }^{1}$, Yi HU ${ }^{1^{\star}}$, Bo XIA ${ }^{3}$, Martin SKITMORE ${ }^{1,3}$, Xianyi GAO ${ }^{1}$ \\ ${ }^{1}$ Research Institute of Complex Engineering and Management, School of Economics and Management, \\ Tongji University, 1 Zhangwu Road, Shanghai, 200092, China \\ ${ }^{2}$ Department of Construction Science, Texas A \& M University, Francis Hall, College Station, TX 77843, U.S.A. \\ ${ }^{3}$ School of Civil Engineering and Built Environment, Queensland University of Technology (QUT), \\ Gardens Point, Brisbane, QLD 4001, Australia
}

Received 28 October 2018; accepted 08 April 2019

\begin{abstract}
As a result of growing complexities in the construction industry, system dynamics modeling (SDM) has been increasingly used in construction management $(\mathrm{CM})$ research to explore complicated causal relationships at the various levels of construction and management processes. Given the rapid growth of SDM applications over the past two decades, a systematic review is needed to ascertain the state of the art and further trends in the area. This paper provides the results of a systematic analysis of 103 papers from 41 selected peer-reviewed journals from 1997 to 2016. The contributions of the papers are first analyzed, structured and formulated in terms of the year of publication, software involved, the combined use with other methods, and research design. With the assistance of the a keyword co-occurrence network analysis, eight research topics involving different internal and external complexities are identified, including: (1) sustainability, (2) project planning and control, (3) performance and effectiveness, (4) strategic management, (5) site and resource management, (6) risk analysis and management, (7) knowledge management, and (8) organization and stakeholder management. The analysis results reveal the pivotal role of SDM in streamlining different complicated casual relationships at the activity, project, and industry levels across the eight topics and its significant potential in uncovering the impact of complicated contextual conditions on project planning and control, effectiveness and performance, strategic management, and sustainability at the project and industry levels. Lastly, trends and recommendations for SDM applications are provided for future $\mathrm{CM}$ research. This paper provides a state of the art of SDM in CM applications and insights into opportunities and useful references for the future.
\end{abstract}

Keywords: system dynamics modeling, construction management, review.

\section{Introduction}

Over the past two decades, system dynamics modeling (SDM) has been increasingly applied in construction management $(\mathrm{CM})$ research to explore the feedback and interaction of factors in construction activities, as shown in Figure 2, reported later. A similar challenge is faced by construction engineering and management as increasing construction scales and ever-changing construction environments have increased the complexity and process dynamics of construction activities and projects (Ogunlana, Li, \& Sukhera, 2003). Theoretically, these construction systems can be further conceptualized as a collection of complex and dynamic interdependent components, including multiple feedback processes and nonlinear re- lationships (Ozcan-Deniz \& Zhu, 2016). SDM provides a powerful way to model the relationships in complicated construction systems, and explore feedback processes and their causal relationships. Such method is pivotal to secure construction efficiency and performance.

From a systems perspective, the construction system involves an accumulating and evolving behavioral process of on-site progress and resources that need to provide response feedback to maintain required performance levels (Lyneis \& Ford, 2007). SDM has an extremely strong ability to deal with behavioral factors of construction systems and their interactions with construction processes (Rodrigues \& Bowers, 1996), especially for those involved in a

${ }^{\star}$ Corresponding author. E-mail: yi_hu@tongji.edu.cn 
megaproject delivery. This advantage cannot be obtained from most traditional modeling methods (e.g.-work breakdown structures, Gantt charts, PERT/CPM networks, project crashing analysis and trade-off analysis) owing to their limited functions (Love, Holt, Shen, Li, \& Irani, 2002).

Despite the significance of SDM in addressing construction-related problems and the care needed in the correct use of this technique, no critical review has yet been undertaken to provide a systemic understanding of its use in CM research. Accordingly, this study conducts a comprehensive review of SDM applications through a robust content analysis of peer-reviewed journal papers. Through a comprehensive literature review, this study aims to: (1) ascertain the annual productivity of SDM research published in leading CM journals between 1997 and 2016, (2) uncover the topic coverage of SDM research regarding different complexity issues in CM, (3) explore the combined use of SDM with other methods and the main research design involved, and (4) identify future directions of SDM applications in CM.

\section{SDM applications in CM research}

SDM is a modeling method used to explore and understand a complex system in a holistic manner by ascertaining its feedback structures and resultant behavior (Sterman, 2000). The method was first proposed in 1958 by Forrester at the Massachusetts Institute of Technology (MIT) to explore the dynamics of industrial systems. In the past two decades, SDM has evolved into a pivotal approach to modeling the behavior and characteristics of complex systems in terms of internal feedback (Sterman, 1992, 2000; Yuan \& Wang, 2014). The method can solve macro-level problems while avoiding micro-level fragmented details (Sterman, 2000; Ko \& Chung, 2014). Thus, it is suitable for handling multi-level complex systems (e.g., modern corporations and social organizations) (Ko \& Chung, 2014).

SDM has developed into an important area in the construction engineering and related fields in preference to quantitative system modeling methods due to its combination of systems theory and computer simulation (Lyneis \& Ford, 2007; Lee, Han, \& Peña-Mora, 2009; Moradi, Nasirzadeh, \& Golkhoo, 2015). It can incorporate the technical, organizational, human, and environmental factors involved in dynamic system processes while simulating the behavior of major outputs of a system over time (Lyneis \& Ford, 2007). Enabled by the rapid development of SDMrelated software in the last two decades, SDM has been increasingly applied in construction engineering areas, such as transportation engineering (Shepherd, 2014), mining engineering (Yang, Love, Brown, \& Spickett, 2012), and gas engineering ( $\mathrm{Hu}$, Zhang, Ma, \& Liang, 2010).

SDM is suited to CM research because of its ability to analyze the interrelationships and feedbacks that exist within complex systems (Sterman, 2000, 2001; Thomas, Menassa, \& Kamat, 2016). It can deal with issues in systems with highly dynamic complexity, derived from inter- actions between interrelated components that evolve over time, such as stocks and flows, time delays, nonlinearities, and feedback loop structures (Terouhid \& Ries, 2016). In addition, the project organization can be viewed as a complex system (Sheng \& Lin, 2018), and SDM can make sub-systems interrelated to pursue and reach project goals (Love et al., 2002). Thus, SDM can be widely used in CM research owing to the characteristics of the construction process and its organization. With the help of SDM modeling, construction project managers can react appropriately to changes, and understand how they influence the behavior of the entire project system (Love et al., 2002). An increasing number of studies have suggested the use of SDM in current CM research, such as planning project activities, managing construction risks, and identifying the causes of rework (Rodrigues \& Bowers, 1996; Love, Mandal, \& Li, 1999; Love, Mandal, Smith, \& Li, 2000; Love et al., 2002; Nasirzadeh, Afshar, \& Khanzadi, 2008a).

\section{Research method}

\subsection{Data collection}

$\mathrm{CM}$ research is a combination of multiple disciplines covering technical and managerial topics (Xiong, Skitmore, \& Xia, 2015). Thus, a comprehensive search method for SDM journal papers is necessary. Meanwhile, the identified papers were necessarily selected through a rigorous process as the foundation of research.

In stage 1 , to ensure search comprehensiveness, the Scopus database is used as the search source because it includes all the leading CM journals and other journals publishing CM papers (Ke, Wang, Chan, \& Cheung, 2009; Xiong et al., 2015; Zhang, Chan, Feng, Duan, \& Ke, 2016b). In this study, only journal papers were selected for analysis, whereas book reviews, editorials and conference papers were excluded. Journal papers usually provide more comprehensive and higher-quality information than other types of publications, and most reviews of CM studies solely focus on journal papers (Zhao, 2017). Adopting the same process as Xiong et al. (2015), the key search words of "system dynamics" and "construction" were used. The full search code is as follows:

(TITLE-ABS-KEY ("system dynamics") AND TITLEABS-KEY (construction) AND LANGUAGE (english)) AND DOCTYPE (ar OR re) AND SUBJAREA (mult

OR ceng OR chem OR comp OR eart OR ener OR engi

OR envi OR mate OR math OR phys OR mult OR arts

OR busi OR deci OR econ OR psyc OR soci)

(time: 2017-12-21).

The above search identified 373 potential SDM papers in CM from 1997 to 2016. Then, another review of these papers was carried out in terms of the following criterion: (a) all papers are peer-reviewed journal papers related to CM issues, and (2) the SDM is a main research method used. This review reduced the number of papers to a final number of 103. These were closely examined to reveal the 


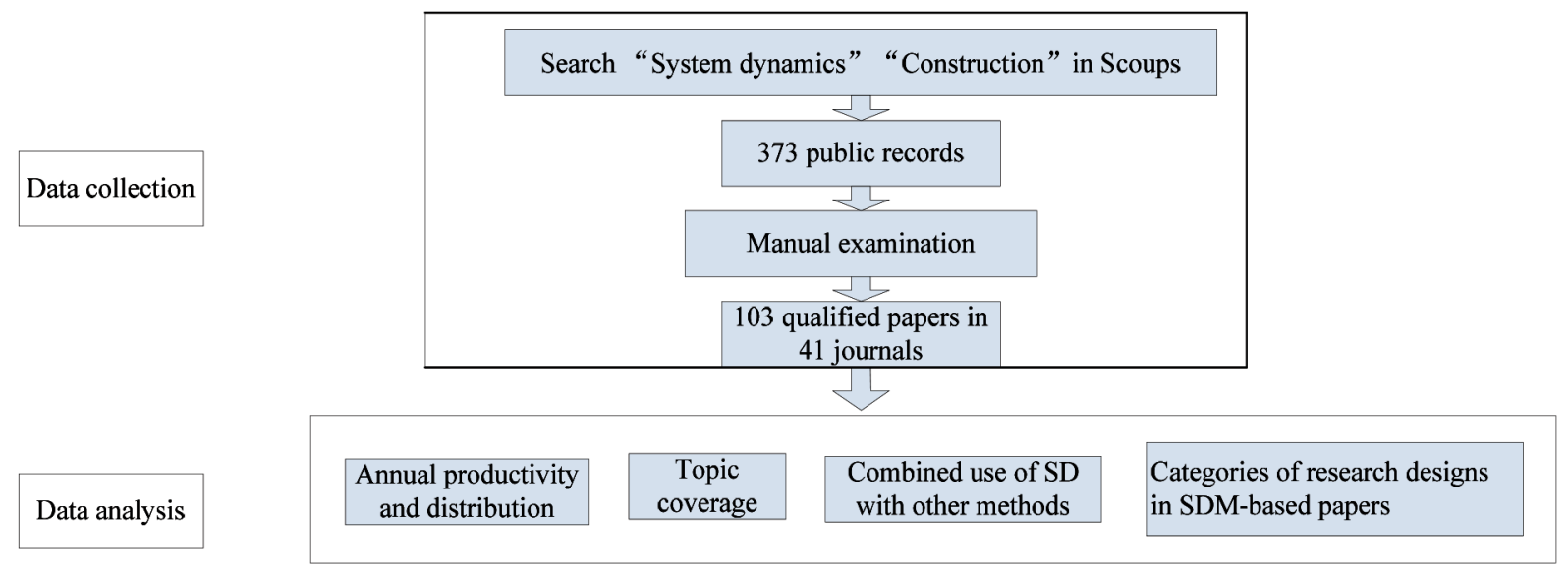

Figure 1. The research process

trends and topic coverage of SDM-based papers to obtain a holistic picture of the SDM applications involved.

\subsection{Data analysis}

A hybrid research methodology was adopted to achieve four purposes, respectively. First, annual productivity analysis was conducted to understand the basic trend and changes of SDM research between 2007 and 2016. This method has been commonly advocated used in previous reviews regarding CM issues (Zheng, Le, Chan, $\mathrm{Hu}, \& \mathrm{Li}$, 2016; Hu, Xia, Skitmore, \& Chen, 2016). Second, a topic coverage analysis was undertaken to determine the major topics involved, which may reveal the application potential of SDM. CiteSpace software, one of the most frequently used scientometric technique, was used to assistant in analyzing the keyword co-occurrence network of the papers (Hosseini et al. 2018), which has been increasingly advocated in recent reviews (e.g. Zheng et al., 2016; Zhao, 2017; Hosseini et al., 2018). Keywords are direct expression of the core content of papers and provide a clue to the topic covered (Hosseini et al., 2018). Third, the combined use of SDM with other advanced methods were evaluated, which may reflect latest trend in the application of SDM to strong and reliable findings. Last, an in-depth analysis was undertaken in the research design of the identified 103 papers.

The overall research process and procedure is illustrated in Figure 1.

\section{Discussion of the analysis results}

\subsection{Annual productivity of the SDM research}

As shown in Figure 2, although fluctuating in the process, the number of SDM-based journal papers increased since 1997. This finding is particularly apparent over the last decade, showing that the SDM is becoming more popular and has wide application in CM.

Table 1 shows the number of papers published each year between 1997 and 2016. The majority are contained in leading CM journals (see Chau, 1997), such as the Jour- nal of Construction Engineering and Management (JCEM), Construction Management and Economics (CME), and the International Journal of Project Management (IJPM). Other leading journals, such as the European Journal of Operational Research (EJOR), Accident Analysis and Prevention (AAP), and System Dynamics Review (SDMR) have also published CM papers. Table 1 further shows the article distribution and percentage of identified papers in these journals.

\subsection{Complexity-related topic coverage}

CiteSpace $5.1 R 8$ was used to visualize the keyword co-occurrence network as shown in Figure 3. The results involve 104 nodes and 110 edges. The network's density is 0.0211 , and thus it is regarded as a sparse network. The node size refers to the frequency of keyword co-occurrence and the edge refers to the two different keywords that together reflect a main theme. The 10 most frequently occurring keywords are "simulation", "project management", "performance", "Hong Kong", "waste management", "policy", "feedback", "demolition waste", "rework", and "sustainability". The high frequency keywords also include the United States and China, which indicates the popularity of SDM in $\mathrm{CM}$ research in these countries.

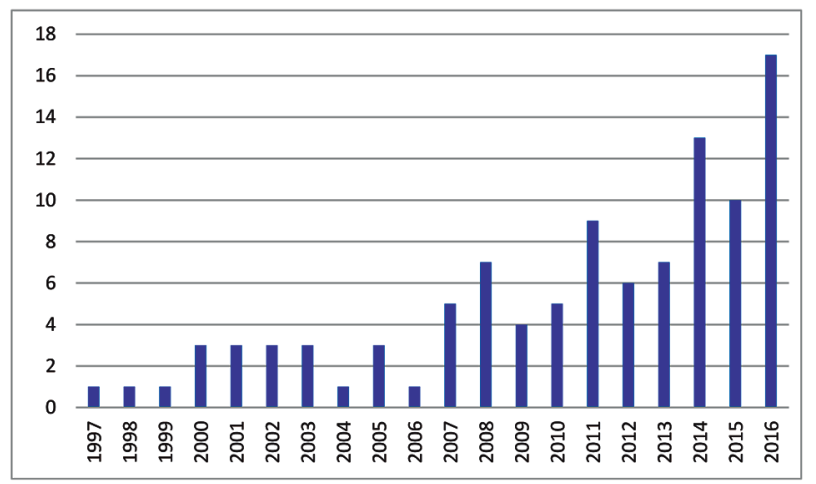

Figure 2. Number of related papers published between 1997 and 2016 
Table 1. Article distribution and percentage of identified papers in significant journals

\begin{tabular}{|c|c|c|c|c|c|}
\hline & 1997-2001 & 2002-2006 & 2007-2011 & 2012-2016 & Total \\
\hline JCEM & 2 & 2 & 6 & 8 & 18 \\
\hline Percentage & $1.94 \%$ & $1.94 \%$ & $5.83 \%$ & $7.77 \%$ & $17.48 \%$ \\
\hline CME & 2 & 2 & 3 & 1 & 8 \\
\hline Percentage & $1.94 \%$ & $1.94 \%$ & $2.91 \%$ & $0.97 \%$ & $7.77 \%$ \\
\hline IJPM & 1 & 1 & 0 & 4 & 6 \\
\hline Percentage & $0.97 \%$ & $0.97 \%$ & $0.00 \%$ & $3.88 \%$ & $5.83 \%$ \\
\hline RCR & 0 & 0 & 2 & 4 & 6 \\
\hline Percentage & $0.00 \%$ & $0.00 \%$ & $1.94 \%$ & $3.88 \%$ & $5.83 \%$ \\
\hline $\mathrm{CI}$ & 0 & 3 & 2 & 0 & 5 \\
\hline Percentage & $0.00 \%$ & $2.91 \%$ & $1.94 \%$ & $0.00 \%$ & $4.85 \%$ \\
\hline ECAM & 1 & 0 & 4 & 0 & 5 \\
\hline Percentage & $0.97 \%$ & $0.00 \%$ & $3.88 \%$ & $0.00 \%$ & $4.85 \%$ \\
\hline JME & 0 & 0 & 2 & 3 & 5 \\
\hline Percentage & $0.00 \%$ & $0.00 \%$ & $1.94 \%$ & $2.91 \%$ & $4.85 \%$ \\
\hline AIC & 0 & 2 & 2 & 0 & 4 \\
\hline Percentage & $0.00 \%$ & $1.94 \%$ & $1.94 \%$ & $0.00 \%$ & $3.88 \%$ \\
\hline AAP & 0 & 0 & 0 & 3 & 3 \\
\hline Percentage & $0.00 \%$ & $0.00 \%$ & $0.00 \%$ & $2.91 \%$ & $2.91 \%$ \\
\hline CJCE & 0 & 0 & 1 & 2 & 3 \\
\hline Percentage & $0.00 \%$ & $0.00 \%$ & $0.97 \%$ & $1.94 \%$ & $2.91 \%$ \\
\hline JCCE & 0 & 1 & 1 & 1 & 3 \\
\hline Percentage & $0.00 \%$ & $0.97 \%$ & $0.97 \%$ & $0.97 \%$ & $2.91 \%$ \\
\hline WM & 0 & 1 & 1 & 1 & 3 \\
\hline Percentage & $0.00 \%$ & $0.97 \%$ & $0.97 \%$ & $0.97 \%$ & $2.91 \%$ \\
\hline Other journals & 3 & 1 & 8 & 22 & 34 \\
\hline Percentage & $2.91 \%$ & $0.97 \%$ & $7.77 \%$ & $21.36 \%$ & $33.01 \%$ \\
\hline
\end{tabular}

Notes: JCEM - Journal of Construction Engineering and Management; CME - Construction Management and Economics; IJPM - International Journal of Project Management; RCR - Resources, Conservation and Recycling; CI - Construction Innovation; ECAM - Engineering, Construction and Architectural Management; JME - Journal of Management in Engineering; AIC - Automation in Construction; AAP - Accident Analysis and Prevention; CJCE - Canadian Journal of Civil Engineering; JCCE - Journal of Computing in Civil Engineering; WM - Waste Management.

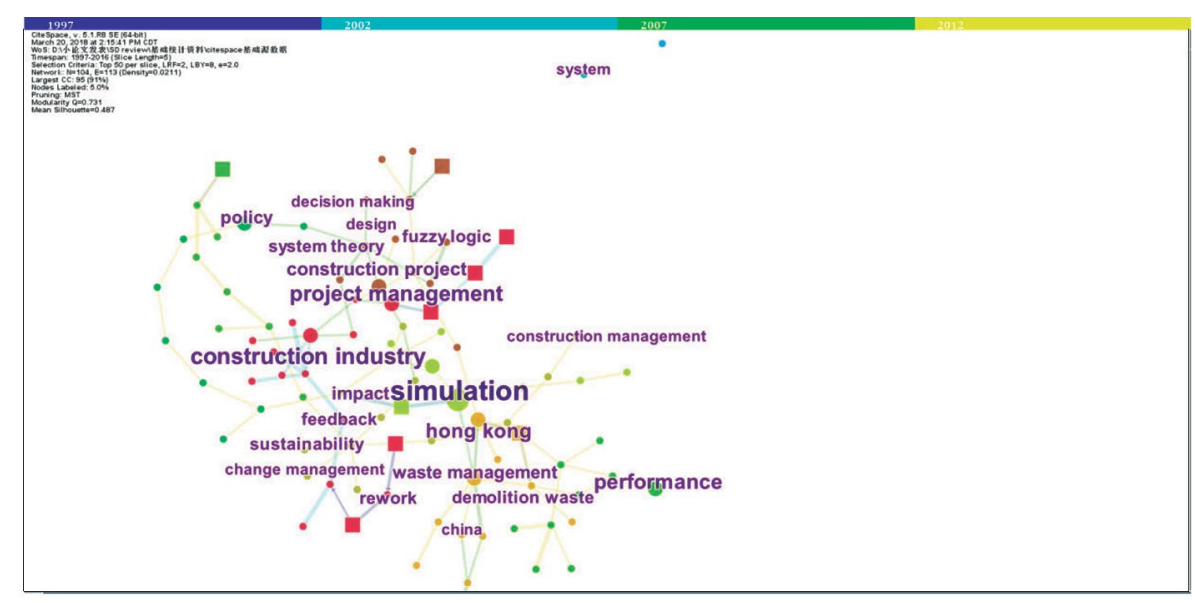

Figure 3. Keyword co-occurrence network 


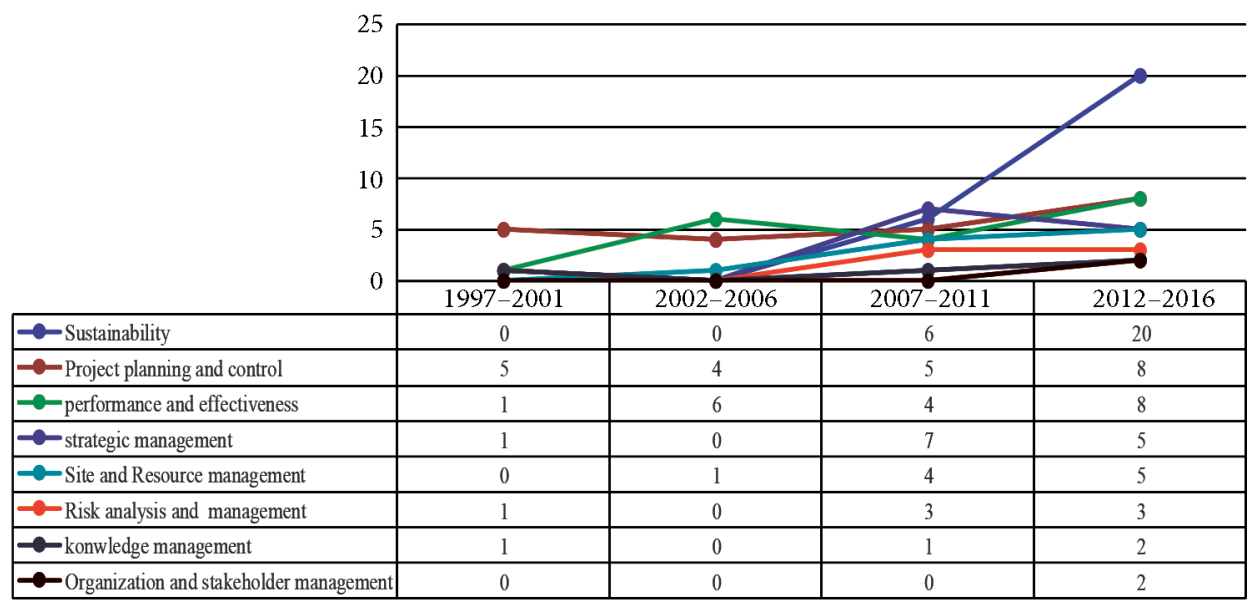

Figure 4. Change in topic coverage over time

Each of the identified papers was thoroughly examined to identify its main research topic by using the scientometric technology. In case that a paper involved more than one topic, only one topic with the best fit was selected $(\mathrm{Hu}$, Chan, Le, \& Jin, 2015; Zheng et al., 2016) in combination with the keywords identified through the co-occurrence network. Considering SDM has a distinct advantage in dealing with CM complexity, especially with risk management and organizational issues (Luo, He, Jaselskis, \& Xie, 2017). Accordingly, this study made an evaluation of the topic coverage of selected SDM topics in terms of project complexity classification For the definition and classification of complexity (internal and external), see $\mathrm{Hu}$ et al. (2015). Finally, on the basis of the results of the keyword co-occurrence network analysis, a total of eight topics were identified, namely (1) sustainability; (2) project planning and control; (3) performance and effectiveness; (4) strategic management; (5) site and resource management; (6) risk analysis and management; (7) knowledge management; and (8) organization and stakeholder management. Figure 4 shows the trend in topic coverage in the four time-slices from 1997 to 2016. Table 2 shows the complexity analysis results of SDM in CM.

Table 2. The eight topics and types of complexity issues

\begin{tabular}{|l|c|c|}
\hline \multirow{2}{*}{\multicolumn{1}{|c|}{ Topics }} & \multicolumn{2}{c|}{ Complexity } \\
\cline { 2 - 3 } & Internal & External \\
\hline Sustainability & 12 & 14 \\
\hline Project Planning and Control & 21 & 1 \\
\hline Performance and Effectiveness & 13 & 6 \\
\hline Strategic Management & 6 & 7 \\
\hline Site and Resource Management & 8 & 2 \\
\hline Risk Analysis and Management & 7 & 0 \\
\hline Knowledge Management & 4 & 0 \\
\hline $\begin{array}{l}\text { Organization and Stakeholder } \\
\text { Management }\end{array}$ & 2 & 0 \\
\hline Total & 73 & 30 \\
\hline
\end{tabular}

Sustainability attracts the most research attention with 26 papers involved, which has significantly increased from 2012 to 2016. Based on the research content analysis, from 2007 to 2011, sustainability mainly focused on waste and demolition management. For example, Yuan, Shen, Hao, and $\mathrm{Lu}$ (2011) used SDM to streamline internal relationships in evaluating the costs and benefits of construction and demolition waste management. From 2012 to 2016, in addition to the constant themes of the internal complexities of waste management from material deterioration (Thomas et al., 2016), the availability of resources (OzcanDeniz \& Zhu, 2016), and waste generation and recycling (Yuan \& Wang, 2014), SDM was expanded to carbon emission reduction (J. Sim \& J. Sim, 2016), nuclear power development (X. Guo \& X. Guo, 2016), prefabrication ( $\mathrm{Li}$, Shen, \& Alshawi, 2014), and the interactions between management complexity and macro-policy complexity were examined by SDM.

Project planning and control, mainly relating to cost/ schedule control and change management, is the second most popular topic. The number of papers on this topic has been relatively stable over the four 5 -year periods. These studies often use SDM to explore the complicated relationships between internal activities and their feedback in solving problems (e.g., Sing, Love, Edwards, \& Liu, 2016; Parvan, Rahmandad, \& Haghani, 2015) as shown in Table 2. Chapman's (1998) study piloted the application of SDM in this area by examining the decrease in design productivity because of staff changes. From 1997 to 2001, the main SDM application focus in this area was on dynamic planning and construction rework. For example, Pena-Mora and Park (2001) and Pena-Mora and Li (2001) developed SDM-based dynamic planning methods for fast-tracking building construction projects, whereas Love et al. (1999) explored the causal structure of construction rework influences. SDM was gradually extended to web-enabled SDM (Lee, Pena-Mora, \& Park, 2006), early-warning and forecasting systems (Huang \& Wang, 2005), cash flow management strategies (Cui, Hastak, \& Halpin, 2010), decision making from an integrated system 
(Motawa, Anumba, Lee, \& Peña-Mora, 2007), and learning (Love, Edwards, \& Irani, 2008). From 2012 to 2016, SDM was widely used in addressing new concepts (e.g., lean production) and with an emphasis on CM issues at the macro level. For example, a new design workflow based on SDM was proposed, using lean concepts to smoothen design work, reduce unnecessary design errors, and increase design reliability (Ko \& Chung, 2014). Schedule delays and cost overruns in design and construction projects at the macro level were systematically evaluated with the assistance of a SDM-based model for analysis (Han, Lee, \& Pena-Mora, 2012).

Performance and effectiveness is ranked third, with 19 papers involved, with SDM helping to optimize management plan changes and policy making to enhance project performance in a real-world setting (Moonseo \& PeñaMora, 2003). Chasey, Garza, and Drew (1997) first used SDM to evaluate the capacity of infrastructure maintenance systems in addressing their complex nature involving multiple feedback loops. Subsequently, an increasing number of studies were devoted to this topic, especially those related to performance at the organizational level. For example, Tang and Ogunlana (2003a, 2003b), for example, examined how to develop and implement improvement policies to enhance organizational performance from a senior manager's perspective based on a SDMbased case study of a publicly listed construction organization. Ogunlana et al. (2003), on the other hand, used SDM to integrate engineering processes and local influencing factors to simulate the performance of construction firms. SDM was also used for performance evaluation at the project level, such as the performance of construction enterprise resource planning systems (Tatari, Castro-Lacouture, \& Skibniewski, 2008), the effectiveness of contractors' bidding management (Lo, Lin, \& Yan, 2007), construction quality management (Nasirzadeh, Khanzadi, Afshar, \& Howick, 2013), labor productivity (Nasirzadeh \& Nojedehi, 2013), the impact of design rework on project performance (Li \& Taylor, 2014), and the effectiveness of contractors' green innovation (Hsueh \& Yan, 2013). Based on these studies, both the impacts of internal and external complexities on organizational/project performance can be streamlined using SDM.

Strategic management is ranked fourth, with 13 papers involved. As construction projects are a man-made goaloriented open system, they tend to be unpredictable and changeable. The complexities of construction projects and their environments trigger the disruptive effect of subjective human factors, which cannot be addressed solely by the experience of individuals, and SDM provides a systematic understanding of the strategic issues involved (Rodrigues \& Bowers, 1996). SDM applications on this topic are grouped under the macro and micro levels. At the macro level, prior research focuses on government and company value-engineering policies (Park, Ahn, Lee, \& Yoon, 2012), urban-land use policy changes (Wu, Zhang, \& Shen, 2011), strategies for the design-build industry (Park, Ji, Lee, \& Kim, 2009), and strategic-operational CM (Peña-Mora,
Han, Lee, \& Park, 2008), which emphasizes on the exploration of the external complexities of project management. At the micro level, SDM is mainly used to analyze internal complexities, such as design strategies for construction waste minimization (Wang, Li, \& Tam, 2015), managing the consequences of cost overruns and schedule delays (Peña-Mora et al., 2008), and the complex interactions of construction operations (Lee et al., 2009). Therefore the SDM can be widely in this topic, whether in the macro or micro levels, to analyze the strategic goals of construction projects by connecting the external and internal complexities.

Site and resource management, which is related to safety and resource management, is ranked fifth with 10 papers involved. SDM applications in this area mainly involved dynamic resource management (Park, 2005), equipment management (Prasertrungruang \& Hadikusumo, 2009), construction operation management (Lee et al., 2009), and safety management (Han, Saba, Lee, Mohamed, \& PeñaMora, 2014). In particular, the topic of safety management is related to an integrated method for safety performance in construction operations (Han et al., 2014), workers' safety attitudes and behaviors (Shin, Lee, Park, Moon, \& Han, 2014), and construction safety behavior patterns (Guo, Yiu, \& González, 2015) from a systems perspective. "Systems thinking" is widely accepted as an effective tool to conceptualize a group of complexity factors and their dynamics of safety management (Guo et al., 2015). The papers involved in this topic are more focused on the internal complexities (8 of 10 papers) of construction activities, especially for safety management (e.g., Guo et al., 2015; Shin et al., 2014; Han et al., 2014).

Risk analysis and management is an important area for SDM applications. As a large number of risk factors usually involve complex casual-loop relationships, SDM is very suited to analyze such relationships, with a number of risk analysis treatments, such as tunnel construction risk analysis (Wang, Ding, Love, \& Edwards, 2016), and risk allocation between owners and their contractors (Nasirzadeh, Khanzadi, \& Rezaie, 2014). As shown in Table 2, the SDM applications in this topic mainly focus on the risks factors related to internal complexities.

Knowledge management received only minor attention with four papers involved. In an early application, SDM was used in a learning organization to represent singleloop learning and double-loop learning (Senge, 1991). From 2000, knowledge management has become a major topic in SDM papers, such as in strategic learning in a dynamic environment (Chen \& Fong, 2013) and experience transfer in complex learning systems (Lê \& Low, 2009), especially combined with organization behavior (Bajracharya, Ogunlana, \& Bach, 2000).

The topic of organization and stakeholder management involves only two SDM-based papers. These are concerned with organizational capabilities and excellence (Terouhid \& Ries, 2016) and employee work-family conflict management (Wu, Duan, Zuo, Yang, \& Wen, 2016), both involving internal complicated causal relationships. Organization 
adaptability is the ability to adapt to changes in contextual complexity (Luo et al., 2017), and thus future SDM applications may be well directed at this issue.

The discussions above indicate that the SDM papers involve internal and external complexity issues across all eight topics. Table 2 reveals a distinct advantage of SDM in handling CM complexity issues. Two topics of project planning and control, and performance and effectiveness were maintained across the four time periods of 1997-2016 as shown in Figure 4. This finding indicates that dominating methodological role of SDM accepted by researchers in these areas. In addition, $71 \%$ of the identified 103 papers involved internal complexity issues in CM, especially with site and resource management, risk analysis and management, knowledge management, project planning and control, performance and effectiveness, and organization and stakeholder management. SDM application has an emphasis on external complexity issues involving industrial policy, regarding sustainability and strategic management.

\subsection{Combined use of SDM with other methods}

Some studies have attempted to combine SDM with other methods such as networks, fuzzy logic, discrete event simulation (DES), and agent-based simulation to provide complementary support by solving the complex problems involved (Rodrigues \& Williams, 1998).

Incorporating the fundamental concepts and principles of network-based tools, such as CPM, PDM, and PERT into the SDM can provide traditional planning tools with more flexibility and functionality (Moonseo \& PeñaMora, 2003). These network-based tools include BP neural networks (Zhang, Schmidt, Xie, \& Li, 2016a), cognitive mapping (CM) (Love, Edwards, \& Smith, 2016), Bayesian belief networks (Wang et al., 2016), and the dynamic planning and control methodology (DPM) (Park, 2005; Lee, Peña-Mora, \& Park, 2005). These tools can effectively solve CM's complex problems.

The SDM result is obtained through simulation methods, such as agent simulation which can also be combined with SDM (Peña-Mora et al., 2008; Lee et al., 2009). Using such professional SDM software as Vensim, other simulation methods can help SDM solve complex problems. These simulation tools include discrete event simulation (DES) (Peña-Mora et al., 2008; Lee et al., 2009; Alvanchi, Lee, \& AbouRizk, 2011; Alvanchi, Lee, \& AbouRizk, 2012; Moradi et al., 2015; Hwang, Park, H. S. Lee, \& S. Lee, 2016) multi-agent decision-making components (Ozcan-Deniz \& Zhu, 2016), and agent-based computational economics (ACE) (Yan, 2015).

The imprecise and uncertain nature of many CM factors means that the traditional deterministic SDM may not always be an appropriate modeling tool (Nasirzadeh et al., 2008a; Nasirzadeh, Afshar, Khanzadi, \& Howick, 2008b; Nasirzadeh et al., 2013, 2014). Fuzzy logic is sometimes integrated into the SDM structure to account for this, forming a fuzzy-SDM model to accommodate the uncertainties involved (Nasirzadeh et al., 2013). The application of Za- deh's extension principle and interval arithmetic has been proposed for the SDM to enable the system outcomes to take into account uncertainties in the input variables $(\mathrm{Na}-$ sirzadeh et al., 2014). The fuzzy-SDM model is widely used for risk management (Nasirzadeh et al., 2008a, 2008b) owing to the imprecise and uncertain nature of risks involved.

Data processing methods are often combined with SDM as collected data cannot be used directly. Several methods, such as factor analysis (Zhang et al., 2016a), time-series forecasting models, regression techniques, judgement techniques (Sing et al., 2016), and AHP (Perng, Hsia, \& Lu, 2007), have been used to formulate raw data to provide the necessary data for the SDM.

\subsection{Categories of research designs of the SDM papers}

Identifying complexity factor and its constructs is the basis of SDM applications in CM research. Meanwhile, research process objectives and it's the level of analysis is another research design factor. CM research using SDM faces the following dilemma (Sterman, 1992): if a simple model is built, then it is criticized for ignoring real-world complex relationships; if a complex model is built instead, then it is criticized for being a 'black box' that no one can understand or check it's working. Thus, the model building process, especially research process objectives, depends on the necessity and practicality of the research (Richardson, 1986). Therefore, balancing complex factors (complexity) and practicality (suitable level of analysis) is significant for SDM applications in CM. An in-depth analysis was conducted to evaluate the design of the identified SDM papers in Table 3. This finding shows that most selected SDM papers focus on the activity (62\%) and project levels (18.5\%).The industry-level papers only involve three topics: sustainability, performance and effectiveness, and strategic management. These topics do not only need SDM to explore micro-level but also emphasize its macro research objectives. Of the eight topics involved, only strategic management is more focused on the industry-level.

Table 3. Categories of research design in SDM-based papers

\begin{tabular}{|l|c|c|c|}
\hline \multirow{2}{*}{\multicolumn{1}{|c|}{ Topic }} & \multicolumn{3}{c|}{ Level of analysis } \\
\cline { 2 - 4 } & Activity & Project & Industry \\
\hline Sustainability & 13 & 6 & 7 \\
\hline Project Planning and Control & 20 & 2 & 0 \\
\hline Performance and Effectiveness & 7 & 6 & 6 \\
\hline Strategic Management & 2 & 4 & 7 \\
\hline Site and Resource Management & 9 & 1 & 0 \\
\hline Risk Analysis and Management & 7 & 0 & 0 \\
\hline Knowledge Management & 4 & 0 & 0 \\
\hline $\begin{array}{l}\text { Organization and Stakeholder } \\
\text { Management }\end{array}$ & 2 & 0 & 0 \\
\hline Total & 64 & 19 & 20 \\
\hline
\end{tabular}


Although SDM is a quantitative method for dealing with complex problems in CM, it can also be used to provide an analysis and explanatory framework to explore the complex CM relationships. SDM is used as a qualitative method to explain behavioral logic in CM for 16 of the selected papers (e.g., Park et al., 2012).

Computer simulation is an indispensable part in SDM research and can overcome the limitations of mental models as it: (i) is explicit and their assumptions are open to review; (ii) is able to interrelate many factors simultaneously; and (iii) can be carried out under controlled conditions, allowing analysts to conduct experiments that are not feasible or ethical in the real system (Love et al., 2000). The early computer languages for SDM were SIMPLE and DYNAMO from the 1950s. These languages were transformed into software owing to the development of the Windows operating system, the most famous software still being STELLA/iThink, Vensim, Powersim, and AnyLogic from the 1990s. Vensim (52 papers, 50.49\%) and iThink (30 papers, 29.13\%) are the most popular in our sample, with Vensim being especially widely used because of its friendly interface and ease of use (Wang et al., 2015).

\section{Evaluation of current research and future directions}

On the basis of the earlier discussions, a dual-dimensional framework involving the types of complexity and unit of analysis is proposed to assess previous SDM research and identify future directions in CM. SDM is commonly used to tackle internal complexity issues in $\mathrm{CM}$ at the activity and project levels (Boxes I and III), which are evidenced by the majority of the papers (68/103) as shown in Figure 5. Early SDM applications were in the area of project rework and then spread to other topics, such as project planning and control, site and resource management, risk analysis and management, and knowledge management.
Exploring internal complexity issues at the activity level does not only involves traditional topics (e.g., project planning and control, and performance and effectiveness), but also several emerging topics, such as sustainability, as shown in Box (I). These applications indicate the strong ability of SDM in ascertaining the complicated causal relationships of activities at the micro level.

Boxes (II) and (IV) indicate that another major application of SDM, as evidenced by 14 papers involved, is in uncovering the impact of contextual complexity (e.g. policy changes, industrial norms, and law requirements) on project activities and arrangements, especially with the topics on project sustainability, performance, and effectiveness (e.g., Onat, Egilmez, \& Tatari, 2014; Tam, Li, \& Cai, 2014). In particular, SDM has been regarded as a leading method for investigating the impact of external policies on sustainability issues (9/14) (Levitt, 2007). Recognizing the dynamic and changeable nature of built environments faced by current CM practice, SDM will have a significant potential to make more contributions in these areas.

Box (III) refers to SDM applications exploring internal complexities at the project level, especially those different project types involved, such as infrastructure (Sing et al., 2016), construction (Lee et al., 2009), and power (Ford, 2001). Although the number of papers (13/103) in this domain is not large, these studies are quite dispersed with five topics involved. This number revealed the ability of SDM to conduct cross-type analysis

Box (VI) refers to the 16 SDM papers that explored external complexities at the industry level. Compared with the SDM studies in Box (I), these papers mainly focus on the influence of external factors (e.g., new policies and technology) on the industry (e.g., Zhang et al., 2016a; J. Sim \& J. Sim, 2016; X. Guo \& X. Guo, 2016; Tang \& Ogunlana, 2003a). The number of papers is small. However it can be an important direction due to such rapid changes at the

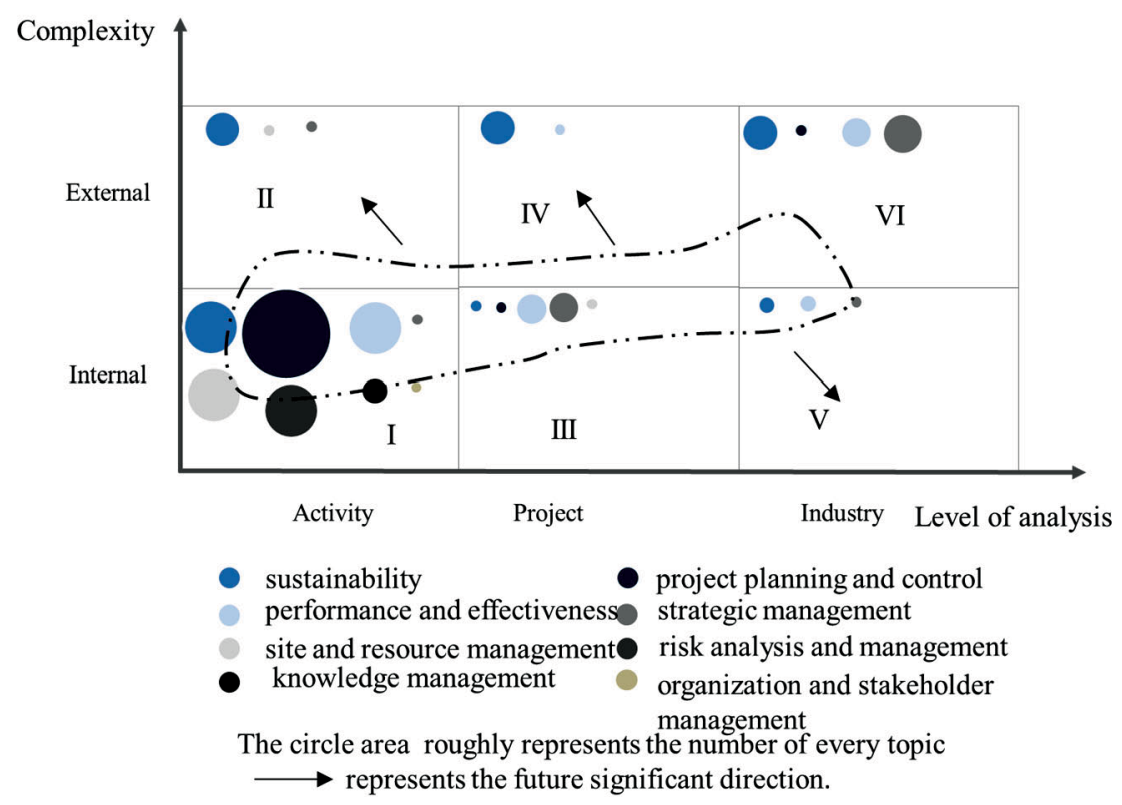

Figure 5. A dual-dimensional framework for evaluating SDM-based research in CM 
industry level, such as new technology (BIM, artificial intelligence and big data) and procurement policies (publicprivate partnerships).

Direction (V) refers to SDM applications in addressing internal complexities at the industry level with five papers involved. These papers mainly look at the impact of macro industrial policies on such micro construction activities as sustainable building developments (Yan, 2015), the design-build model on strategies (Park et al., 2009), and environmental policies on waste reduction management (Ding, Yi, Tam, \& Huang, 2016). These findings reveal the ability of SDM to uncover the interactions and relationships between contextual conditions and micro construction activities. Based on the results above, SDM is widely accepted because of its essential ability in streamlining complicated casual relationships at the activity, project and industry levels and its significant potential in uncovering the impact of contextual complicated conditions on project planning and control, effectiveness and performance, strategic management, and sustainability at the project and industry levels. Recognizing the increasing complexity of the economic, natural, and social environments faced by construction projects and the relatively limited applications of SDM, these areas will represent a significant potential for future SDM applications.

\section{Conclusions}

This systematic review indicates that SDM has been increasingly advocated by researchers over the past two decades to explore nonlinear and dynamic complexity issues involved in CM. The sampled 103 papers indicate that prior efforts can be grouped into eight topics, of: (1) sustainability, (2) project planning and control, (3) performance and effectiveness, (4) strategic management, (5) site and resource management, (6) risk analysis and management, (7) knowledge management, and (8) organization and stakeholder management. In addition, the review results show that these SDM applications involve the use of a mixed method, combining network analysis, fuzzy logics analysis, discrete event simulation, and agent-based simulation. SDM is identified as not only an important approach for streamlining complicated causal relationships across topics at the activity, project, and industry levels, but also for its significant potential in uncovering the impact of contextual complicated conditions in project planning and control, effectiveness and performance, strategic management and sustainability. The research findings present both a holistic knowledge map of SDM applications in CM and insights into opportunities and useful references for future applications of SDM in CM research.

\section{Acknowledgement and funding}

This paper is a redevelopment of an earlier conference paper presented to the 2017 Conference on Innovation in Production and Construction (IPC) at Curtin University, Perth, Australia. The work described was funded by the National Natural Science Foundation of China (Grant
Nos. 71871164, 71841023, 71390523, 71501142), Australian Research Council (ARC) Discovery Project (Grant No. DP170101208), the China Scholarship Council (Grant No. 201706260214), International Cooperation Program for Postgraduates, Tongji University (Grant No. 2019GJXSLT-009), Fundamental Research Funds for the Central University (Grant Nos. 3151910514, 22120180227) and the Shanghai Pujiang Program (Grant No. 16PJ1432400).

\section{Disclosure statement}

The authors would like to declare that they no competing financial, professional, or personal interests from other parties.

\section{References}

Alvanchi, A., Lee, S., \& AbouRizk, S. (2011). Modeling framework and architecture of hybrid system dynamics and discrete event simulation for construction. Computer-Aided Civil and Infrastructure Engineering, 26(2), 77-91.

https://doi.org/10.1111/j.1467-8667.2010.00650.x

Alvanchi, A., Lee, S., \& AbouRizk, S. M. (2012). Dynamics of workforce skill evolution in construction projects. Canadian Journal of Civil Engineering, 39(9), 1005-1017.

https://doi.org/10.1139/12012-087

Bajracharya, A., Ogunlana, S. O., \& Bach, N. L. (2000). Effective organizational infrastructure for training activities: a case study of the Nepalese construction sector. System Dynamics Review, 16(2), 91-112. https://doi.org/10.1002/10991727(200022)16:2<91::AID-SDR190>3.0.CO;2-D

Chapman, R. J. (1998). The role of system dynamics in understanding the impact of changes to key project personnel on design production within construction projects. International Journal of Project Management, 16(4), 235-247. https://doi.org/10.1016/s0263-7863(97)00043-4

Chasey, A. D., Garza, J. M. d. 1., \& Drew, D. R. (1997). Comprehensive level of service: needed approach for civil infrastructure systems. Journal of Infrastructure Systems, 3(4), 143-153. https://doi.org/10.1061/(asce)1076-0342(1997)3:4(143)

Chau, K. W. (1997). The ranking of construction management journals. Construction Management and Economics, 15(4), 387-398. https://doi.org/10.1080/014461997372953

Chen, L., \& Fong, P. S. (2013). Visualizing evolution of knowledge management capability in construction firms. Journal of Construction Engineering and Management, 139(7), 839-851. https://doi.org/10.1061/(asce)co.1943-7862.0000649

Cui, Q., Hastak, M., \& Halpin, D. (2010). Systems analysis of project cash flow management strategies. Construction Management and Economics, 28(4), 361-376. https://doi.org/10.1080/01446191003702484

Ding, Z., Yi, G., Tam, V. W., \& Huang, T. (2016). A system dynamics-based environmental performance simulation of construction waste reduction management in China. Waste Management, 51, 130-141.

https://doi.org/10.1016/j.wasman.2016.03.001

Ford, A. (2001). Waiting for the boom: a simulation study of power plant construction in California. Energy Policy, 29(11), 847-869. https://doi.org/10.1016/s0140-6701(02)86332-9

Guo, B. H., Yiu, T. W., \& González, V. A. (2015). Identifying behaviour patterns of construction safety using system archetypes. Accident Analysis Prevention, 80, 125-141. https://doi.org/10.1016/j.aap.2015.04.008 
Guo, X., \& Guo, X. (2016). Nuclear power development in China after the restart of new nuclear construction and approval: A system dynamics analysis. Renewable and Sustainable Energy Reviews, 57, 999-1007. https://doi.org/10.1016/j.rser.2015.12.190

Han, S., Lee, S., \& Pena-Mora, F. (2012). Identification and quantification of non-value-adding effort from errors and changes in design and construction projects. Journal of Construction Engineering and Management, 138(1), 98-109. https://doi.org/10.1061/(asce)co.1943-7862.0000406

Han, S., Saba, F., Lee, S., Mohamed, Y., \& Peña-Mora, F. (2014). Toward an understanding of the impact of production pressure on safety performance in construction operations. Accident Analysis and Prevention, 68(1), 106.

https://doi.org/10.1016/j.aap.2013.10.007

Hosseini, M. R., Martek, I., Zavadskas, E. K., Aibinu, A. A., Arashpour, M., \& Chileshe, N. (2018). Critical evaluation of off-site construction research: A Scientometric analysis. Automation in Construction, 87, 235-247.

https://doi.org/10.1016/j.autcon.2017.12.002

Hsueh, S. L., \& Yan, M. R. (2013). A multimethodology contractor assessment model for facilitating green innovation: the view of energy and environmental protection. The Scientific World Journal. https://doi.org/10.1155/2013/624340

Hu, J., Zhang, L., Ma, L., \& Liang, W. (2010). An integrated method for safety pre-warning of complex system. Safety Science, 48(5), 580-597. https://doi.org/10.1016/j.ssci.2010.01.007

Hu, X., Xia, B., Skitmore, M., \& Chen, Q. (2016). The application of case-based reasoning in construction management research: An overview. Automation in Construction, 72, 65-74. https://doi.org/10.1016/j.autcon.2016.08.023

Hu, Y., Chan, A. P. C., Le, Y., \& Jin, R. Z. (2015). From construction megaproject management to complex project management: bibliographic analysis. Journal of Management in Engineering, 31(4), 04014052.

https://doi.org/10.1061/(asce)me.1943-5479.0000254

Hwang, S., Park, M., Lee, H. S., \& Lee, S. (2016). Hybrid simulation framework for immediate facility restoration planning after a catastrophic disaster. Journal of Construction Engineering and Management, 142(8), 04016026.

https://doi.org/10.1061/(asce)co.1943-7862.0001146

Huang, F., \& Wang, F. (2005). A system for early-warning and forecasting of real estate development. Automation in Construction, 14(3), 333-342.

https://doi.org/10.1016/j.autcon.2004.08.015

Ke, Y., Wang, S., Chan, A. P., \& Cheung, E. (2009). Research trend of public-private partnership in construction journals. Journal of Construction Engineering and Management, 135(10), 1076-1086.

https://doi.org/10.1061/(asce)0733-9364(2009)135:10(1076)

Ko, C. H., \& Chung, N. F. (2014). Lean design process. Journal of Construction Engineering and Management, 140(6), 04014011. https://doi.org/10.1061/(asce)co.1943-7862.0000824

Lê, M. A. T., \& Law, K. H. (2009). System dynamic approach for simulation of experience transfer in the AEC industry. Journal of Management in Engineering, 25(4), 195-203.

https://doi.org/10.1061/(asce)0742-597x(2009)25:4(195)

Lee, S., Han, S., \& Peña-Mora, F. (2009). Integrating construction operation and context in large-scale construction using hybrid computer simulation. Journal of Computing in Civil Engineering, 23(2), 75-83.

https://doi.org/10.1061/(asce)0887-3801(2009)23:2(75)

Lee, S., Peña-Mora, F., \& Park, M. (2005). Quality and change management model for large scale concurrent design and construction projects. Journal of Construction Engineering and Management, 131(8), 890-902.

https://doi.org/10.1061/(ASCE)0733-9364(2005)131:8(890)

Lee, S. H., Pena-Mora, F., \& Park, M. (2006). Dynamic planning and control methodology for strategic and operational construction project management. Automation in Construction, 15(1), 84-97. https://doi.org/10.1016/j.autcon.2005.02.008

Levitt, R. E. (2007). CEM research for the next 50 years: Maximizing economic, environmental, and societal value of the built environment. Journal of Construction Engineering and Management, 133(9), 619-628.

https://doi.org/10.1061/(asce)0733-9364(2007)133:9(619)

Li, Y., \& Taylor, T. R. (2014). Modeling the impact of design rework on transportation infrastructure construction project performance. Journal of Construction Engineering and Management, 140(9), 04014044.

https://doi.org/10.1061/(asce)co.1943-7862.0000878

Li, Z., Shen, G. Q., \& Alshawi, M. (2014). Measuring the impact of prefabrication on construction waste reduction: an empirical study in China. Resources, Conservation and Recycling, 91, 27-39. https://doi.org/10.1016/j.resconrec.2014.07.013

Lo, W., Lin, C., \& Yan, M. (2007). Contractor's opportunistic bidding behavior and equilibrium price level in the construction market. Journal of Construction Engineering and Management, 133(6), 409-416.

https://doi.org/10.1061/(asce)0733-9364(2007)133:6(409)

Love, P. E., Edwards, D. J., \& Irani, Z. (2008). Forensic project management: An exploratory examination of the causal behavior of design-induced rework. IEEE Transactions on Engineering Management, 55(2), 234-247. https://doi.org/10.1109/tem.2008.919677

Love, P. E., Edwards, D. J., \& Smith, J. (2016). Rework causation: Emergent theoretical insights and implications for research. Journal of Construction Engineering and Management, 142(6), 04016010 . https://doi.org/10.1061/(ASCE)CO.1943-7862.0001114

Love, P. E., Mandal, P., \& Li, H. (1999). Determining the causal structure of rework influences in construction. Construction Management and Economics, 17(4), 505-517. https://doi.org/10.1080/014461999371420

Love, P. E., Mandal, P., Smith, J., \& Li, H. (2000). Modelling the dynamics of design error induced rework in construction. Construction Management and Economics, 18(5), 567-574. https://doi.org/10.1080/014461900407374

Love, P. E. D., Holt, G. D., Shen, L. Y., Li, H., \& Irani, Z. (2002). Using systems dynamics to better understand change and rework in construction project management systems. International Journal of Project Management, 20(6), 425-436. https://doi.org/10.1016/s0263-7863(01)00039-4

Luo, L., He, Q., Jaselskis, E. J., \& Xie, J. (2017). Construction project complexity: Research trends andimplications. Journal of Construction Engineering and Management, 143(7), 04017019. https://doi.org/10.1061/9780784481271.028

Lyneis, J. M., \& Ford, D. N. (2007). System dynamics applied to project management: a survey, assessment, and directions for future research. System Dynamics Review, 23(2-3), 157-189. https://doi.org/10.1002/sdr.377

Moonseo, P., \& Peña-Mora, F. (2003). Dynamic change management for construction: introducing the change cycle into model-based project management. System Dynamics Review, 19(3), 213-242. https://doi.org/10.1002/sdr.273

Moradi, S., Nasirzadeh, F., \& Golkhoo, F. (2015). A hybrid SD-DES simulation approach to model construction projects. Construction Innovation, 15(1), 66-83. https://doi.org/10.1108/CI-10-2013-0045 
Motawa, I., Anumba, C., Lee, S., \& Peña-Mora, F. (2007). An integrated system for change management in construction. Automation in Construction, 16(3), 368-377. https://doi.org/10.1016/j.autcon.2006.07.005

Nasirzadeh, F., Afshar, A., \& Khanzadi, M. (2008a). Dynamic risk analysis in construction projects. Canadian Journal of Civil Engineering, 35(8), 820-831. https://doi.org/10.1139/L08-035

Nasirzadeh, F., Afshar, A., Khanzadi, M., \& Howick, S. (2008b). Integrating system dynamics and fuzzy logic modelling for construction risk management. Construction Management and Economics, 26(11), 1197-1212.

https://doi.org/10.1080/01446190802459924

Nasirzadeh, F., Khanzadi, M., Afshar, A., \& Howick, S. (2013). Modeling quality management in construction projects. International Journal of Civil Engineering, 11(1), 14-22.

Nasirzadeh, F., Khanzadi, M., \& Rezaie, M. (2014). Dynamic modeling of the quantitative risk allocation in construction projects. International Journal of Project Management, 32(3), 442-451. https://doi.org/10.1016/j.ijproman.2013.06.002

Nasirzadeh, F., \& Nojedehi, P. (2013). Dynamic modeling of labor productivity in construction projects. International Journal of Project Management, 31(6), 903-911. https://doi.org/10.1016/j.ijproman.2012.11.003

Ogunlana, S. O., Li, H., \& Sukhera, F. A. (2003). System dynamics approach to exploring performance enhancement in a construction organization. Journal of Construction Engineering and Management, 129(5), 528-536.

https://doi.org/10.1061/(asce)0733-9364(2003)129:5(528)

Onat, N. C., Egilmez, G., \& Tatari, O. (2014). Towards greening the US residential building stock: a system dynamics approach. Building and Environment, 78, 68-80.

https://doi.org/10.1016/j.buildenv.2014.03.030

Ozcan-Deniz, G., \& Zhu, Y. (2016). A system dynamics model for construction method selection with sustainability considerations. Journal of Cleaner Production, 121, 33-44. https://doi.org/10.1016/j.jclepro.2016.01.089

Park, M. (2005). Model-based dynamic resource management for construction projects. Automation in Construction, 14(5), 585-598. https://doi.org/10.1016/j.autcon.2004.11.001

Park, M., Ahn, C., Lee, H., \& Yoon, Y. (2012). System dynamics-based strategies to diffuse construction VE in the public sector. KSCE Journal of Civil Engineering, 16(4), 486-498. https://doi.org/10.1007/s12205-012-1226-0

Park, M., Ji, S.-H., Lee, H.-S., \& Kim, W. (2009). Strategies for design-build in Korea using system dynamics modeling. Journal of Construction Engineering and Management, 135(11), 11251137. https://doi.org/10.1061/(asce)co.1943-7862.0000095

Parvan, K., Rahmandad, H., \& Haghani, A. (2015). Inter-phase feedbacks in construction projects. Journal of Operations Management, 39, 48-62. https://doi.org/10.1016/j.jom.2015.07.005

Peña-Mora, F., Han, S., Lee, S., \& Park, M. (2008). Strategicoperational construction management: Hybrid system dynamics and discrete event approach. Journal of Construction Engineering and Management, 134(9), 701-710. https://doi.org/10.1061/(asce)0733-9364(2008)134:9(701)

Pena-Mora, F., \& Li, M. (2001). Dynamic planning and control methodology for design/build fast-track construction projects. Journal of Construction Engineering and Management, 127(1), 1-17. https://doi.org/10.1061/(asce)0733-9364(2001)127:1(1)

Pena-Mora, F., \& Park, M. (2001). Dynamic planning for fasttracking building construction projects. Journal of Construction Engineering and Management, 127(6), 445-457. https://doi.org/10.1061/(asce)0733-9364(2001)127:6(445)
Perng, Y. H., Hsia, Y. P., \& Lu, H. J. (2007). A service quality improvement dynamic decision support system for refurbishment contractors. Total Quality Management Business Excellence, 18(7), 731-749.

https://doi.org/10.1080/14783360701349716

Prasertrungruang, T., \& Hadikusumo, B. H. (2009). Modeling the dynamics of heavy equipment management practices and downtime in large highway contractors. Journal of Construction Engineering and Management, 135(10), 939-947. https://doi.org/10.1061/(ASCE)CO.1943-7862.0000076

Richardson, G. P. (1986). Problems with causal-loop diagrams. System Dynamics Review, 2(2), 158-170. https://doi.org/10.1002/sdr.4260020207

Rodrigues, A., \& Bowers, J. (1996). The role of system dynamics in project management. International Journal of Project Management, 14(4), 213-220. https://doi.org/10.1016/0263-7863(95)00075-5

Rodrigues, A. G., \& Williams, T. M. (1998). System dynamics in project management: Assessing the impacts of client behaviour on project performance. Journal of the Operational Research Society, 49(1), 2-15. https://doi.org/10.1038/sj.jors.2600490

Senge, P. M. (1991). The fifth discipline, the art and practice of the learning organization. Performance Instruction, 30(5), 37. https://doi.org/10.1037//1061-4087.45.4.31

Sheng, Z., \& Lin, H. (2018). From systematicness to complexity: Fundamental thinking of mega-project management. Frontiers of Engineering Management, 5(1), 125-127. https://doi.org/10.15302/J-FEM-2018001

Shepherd, S. P. (2014). A review of system dynamics models applied in transportation. Transportmetrica B, 2(2), 83-105. https://doi.org/10.1080/21680566.2014.916236

Shin, M., Lee, H. S., Park, M., Moon, M., \& Han, S. (2014). A system dynamics approach for modeling construction workers' safety attitudes and behaviors. Accident Analysis Prevention, 68, 95-105. https://doi.org/10.1016/j.aap.2013.09.019

Sim, J. \& Sim, J. (2016). The effect of new carbon emission reduction targets on an apartment building in South Korea. Energy and Buildings, 127, 637-647.

https://doi.org/10.1016/j.enbuild.2016.06.032

Sing, M. C., Love, P., Edwards, D., \& Liu, J. (2016). Dynamic modeling of workforce planning for infrastructure projects. Journal of Management in Engineering, 32(6), 04016019. https://doi.org/10.1061/(ASCE)ME.1943-5479.0000463

Sterman, J. D. (1992). System dynamics modeling for project management. Cambridge: Massachusetts Institute of Technology.

Sterman, J. D. (2001). System dynamics modeling: tools for learning in a complex world. California Management Review, 43(4), 8-25. https://doi.org/10.2307/41166098

Sterman, J. D. (2000). Business dynamics: systems thinking and modeling for a complex world. Boston: Irwin/McGraw-Hill.

Tam, V. W., Li, J., \& Cai, H. (2014). System dynamic modeling on construction waste management in Shenzhen, China. Waste Management Research, 32(5), 441-453. https://doi.org/10.1177/0734242x14527636

Tang, Y. H., \& Ogunlana, S. O. (2003a). Modelling the dynamic performance of a construction organization. Construction Management and Economics, 21(2), 127-136. https://doi.org/10.1080/0144619032000079699

Tang, Y. H., \& Ogunlana, S. O. (2003b). Selecting superior performance improvement policies. Construction Management and Economics, 21(3), 247-256.

https://doi.org/10.1080/0144619032000093765 
Tatari, O., Castro-Lacouture, D., \& Skibniewski, M. J. (2008). Performance evaluation of construction enterprise resource planning systems. Journal of Management in Engineering, 24(4), 198-206.

https://doi.org/10.1061/(ASCE)0742-597X(2008)24:4(198)

Terouhid, S. A., \& Ries, R. (2016). People capability: A strategic capability for enhancing organizational excellence of construction firms. Journal of Modelling in Management, 11(3), 811-841. https://doi.org/10.1108/JM2-04-2014-0028

Thomas, A., Menassa, C. C., \& Kamat, V. R. (2016). System dynamics framework to study the effect of material performance on a building's lifecycle energy requirements. Journal of Computing in Civil Engineering, 30(6), 04016034. https://doi.org/10.1061/(ASCE)CP.1943-5487.0000601

Wang, F., Ding, L., Love, P. E., \& Edwards, D. J. (2016). Modeling tunnel construction risk dynamics: Addressing the production versus protection problem. Safety Science, 87, 101-115. https://doi.org/10.1016/j.ssci.2016.01.014

Wang, J., Li, Z., \& Tam, V. W. (2015). Identifying best design strategies for construction waste minimization. Journal of Cleaner Production, 92, 237-247. https://doi.org/10.1016/j.jclepro.2014.12.076

Wu, Y., Zhang, X., \& Shen, L. (2011). The impact of urbanization policy on land use change: A scenario analysis. Cities, 28(2), 147-159. https://doi.org/10.1016/j.cities.2010.11.002

Wu, G., Duan, K., Zuo, J., Yang, J., \& Wen, S. (2016). System dynamics model and simulation of employee work-family conflict in the construction industry. International Journal of Environmental Research and Public Health, 13(11), 1059. https://doi.org/10.3390/ijerph13111059

Xiong, B., Skitmore, M., \& Xia, B. (2015). A critical review of structural equation modeling applications in construction research. Automation in Construction, 49, 59-70. https://doi.org/10.1016/j.autcon.2014.09.006
Yan, M. R. (2015). Project-based market competition and policy implications for sustainable developments in building and construction sectors. Sustainability, 7(11), 15423-15448. https://doi.org/10.3390/su71115423

Yang, M. G., Love, P. E. D., Brown, H., \& Spickett, J. (2012). Organizational accidents: A systemic model of production versus protection. Journal of Management Studies, 49(1), 52-76. https://doi.org/10.1111/j.1467-6486.2010.00959.x

Yuan, H. P., Shen, L. Y., Hao, J. J., \& Lu, W. S. (2011). A model for cost-benefit analysis of construction and demolition waste management throughout the waste chain. Resources, Conservation and Recycling, 55(6), 604-612. https://doi.org/10.1016/j.resconrec.2010.06.004

Yuan, H., \& Wang, J. (2014). A system dynamics model for determining the waste disposal charging fee in construction. European Journal of Operational Research, 237(3), 988-996. https://doi.org/10.1016/j.ejor.2014.02.034

Zhang, J., Schmidt, K., Xie, H., \& Li, H. (2016a). A new mixed approach for modelling and assessing environmental influences to value co-creation in the construction industry. International Journal of Production Research, 54(21), 65486562. https://doi.org/10.1080/00207543.2016.1145818

Zhang, S., Chan, A. P. C., Feng, Y., Duan, H., \& Ke, Y. (2016b). Critical review on PPP Research - A search from the Chinese and international journals. International Journal of Project Management, 34(4), 597-612.

https://doi.org/10.1016/j.ijproman.2016.02.008

Zhao, X. (2017). A scientometric review of global BIM research: Analysis and visualization. Automation in Construction, 80, 37-47. https://doi.org/10.1016/j.autcon.2017.04.002

Zheng, X., Le, Y., Chan, A. P. C., Hu, Y., \& Li, Y. (2016). Review of the application of social network analysis (SNA) in construction project management research. International Journal of Project Management, 34(7), 1214-1225.

https://doi.org/10.1016/j.ijproman.2016.06.005 